\title{
Health Endpoint Attributed to Sulfur Dioxide Air Pollutants
}

\author{
Sahar Geravandi ${ }^{1,2}$; Gholamreza Goudarzi ${ }^{3,4}$; Ali Akbar Babaei ${ }^{3,4}$; Afshin Takdastan ${ }^{3,4}$; \\ Mohammad Javad Mohammadi ${ }^{3,2,}$; Mehdi Vosoughi Niri ${ }^{3}$; Shokrollah Salmanzadeh ${ }^{5}$; \\ Esmat Shirbeigi ${ }^{6}$ \\ ${ }^{1}$ Department of Nursing, Islamic Azad University, Tehran Medical Sciences Branch, Tehran, IR Iran \\ ${ }_{2}^{2}$ Razi Teaching Hospital, Clinical Research Development Center, Ahvaz Jundishapur University of Medical Sciences, Ahvaz, IR Iran \\ ${ }^{3}$ Department of Environmental Health Engineering, School of Public Health, Ahvaz Jundishapur University of Medical Sciences, Ahvaz, IR Iran \\ ${ }_{5}^{4}$ Department of Environmental Health Engineering, Environmental Technologies Research Center, Ahvaz Jundishapur University of Medical Sciences, Ahvaz, IR Iran \\ 5 Department of Environmental Health Engineering, Environmental Technologies Research Center, Ahvaz Jundishapur University of Medical scie \\ 6 Department of Medicine, Infectious and Tropical Diseases Research Center, Ahvaz Jundishapur University of Medical Sciences, Ahvaz, IR Iran
${ }_{\text {Department }}$ Nutrition, Nutrition and Metabolic Diseases Research Center, Ahvaz Jundishapour University of Medicl Sciences, Ahvaz, IR Iran \\ *Corresponding author: Mohammad Javad Mohammadi, Department of Environmental Health Engineering, School of Public Health, Ahvaz Jundishapur University of Medical \\ Sciences, Ahvaz, IR Iran. Tel: +98-9355439707, E-mail: javad_sam2000@yahoo.com; Mohamadi.m@ajums.ac.ir
}

Received: April 20, 2015; Revised: May 24, 2015; Accepted: June 8, 2015

\begin{abstract}
Background: Sulfur dioxide is a colorless gas, released from burning of coal, high-sulfur coal, and diesel fuel. Sulfur dioxide harms human health by reacting with the moisture in the nose, nasal cavity and throat and this is the way by which it destroys the nerves in the respiratory system.

Objectives: The aim of this study was to focus on identifying the effects associated with sulfur dioxide on health in Ahvaz, Iran.

Materials and Methods: Data collections were performed by Ahvaz meteorological organization and the department of environment. Sampling was performed for 24 hours in four stations. Methods of sampling and analysis were according to US environmental protection agency (EPA) guideline. Afterwards, we processed the raw data including instruction set correction of averaging, coding and filtering by Excel software and then, the impact of meteorological parameters were converted as the input file to the AirQ model. Finally, we calculated the health effects of exposure to sulfur dioxide.

Results: According to the findings, the concentration of sulfur dioxide in Ahvaz had an annual average of $51 \mu \mathrm{g} / \mathrm{m}^{3}$. Sum of the numbers of hospital admissions for respiratory diseases attributed to sulfur dioxide was 25 cases in 2012 . Approximately, $5 \%$ of the total hospital admissions for respiratory disease and respiratory mortality happened when sulfur dioxide concentration was more than $10 \mathrm{mg} / \mathrm{m}^{3}$.

Conclusions: According to the results of this study, this increase could be due to higher fuel consumption, usage of gasoline in vehicles, oil industry, and steel and heavy industries in Ahwaz. The risk of mortality and morbidity were detected at the current concentrations of air pollutants.
\end{abstract}

Keywords: Sulfur Dioxide; Health; Air Pollutants; Hemoglobin; Iran

\section{Background}

Epidemiological and toxicological researches on air pollution have asserted that air pollution is responsible for human health and the rate of death (1-3). Air pollution is a major environmental risk to health (4). The less the air pollution, the better the cardiovascular and respiratory health of the population will be, both long-and short-term (5-7). Several studies have demonstrated the relation between short and long term effects of exposure to air pollutants and human health. The most important effects of air pollution include: increased rates of hospital admissions, asthma attacks, cardiopulmonary diseases, and annual death (8-12). The US national ambient air quality standards (NAAQS) lists air pollutants as carbon monoxide, ozone, particulate matter, sulfur dioxide, nitrogen dioxide and lead. Sulfur dioxide is a colorless gas, released from burning of coal, high-sulfur coal and diesel fuel. $\mathrm{SO}_{2}$ comprises a major portion of the pollutant load in many cities (13-15). It can cause irritation, reduction of visibility and some re- spiratory diseases (16-18). Sulfur dioxide can be dangerous to the respiratory system and the function of the lungs and can also lead to irritation of eyes $(19,20)$. From the past until now, Ahvaz has been well known due to industries as well as environmental pollution. In the last decade, an anthropogenic source of air pollution (dust storm) has joined to other environmental problems (21). Physical, chemical and biological characteristics of dust storm and also identification of hazardous air pollutants (HAPs) such as benzene, toluene, ethyl benzene, and xylenes (BTEX) have been well documented (21-23). Social impacts of dust storm on Ahvaz citizens has also been evaluated $(24,25)$. With the rapid economic growth in Ahvaz, the level of air pollution by both motor vehicles and industrial emissions has drastically increased. Furthermore, health effect of air pollution in terms of sulfur dioxide, ozone and particulate matter in most megacities particularly in Ahvaz has been reported. Pooled, in 12 European cities, estimated an

Copyright (C) 2015, Ahvaz Jundishapur University of Medical Sciences. This is an open-access article distributed under the terms of the Creative Commons Attribution-NonCommercial 4.0 International License (http://creativecommons.org/licenses/by-nc/4.0/) which permits copy and redistribute the material just in noncommercial usages, provided the original work is properly cited. 
increase in daily mortality for an increase of $50 \mu \mathrm{g} / \mathrm{m}^{3}$ in concentrations of sulfur dioxide and particulates, which were $3 \%$ and $2 \%$, respectively (26). In Spokane, where sulfur dioxide concentrations were even lower, Schwartz reported similar findings of a significant health effect of particulates independent of sulfur dioxide (27).

\section{Objectives}

This study was designed to evaluate the association between fluctuations in ambient sulfur dioxide concentrations and hospital admissions of respiratory disease and respiratory mortality in Ahvaz city, southwest of Iran, during 2012.

\section{Materials and Methods}

In this retrospective study, we assessed the potential effects of sulfur dioxide exposure on human health in Ahvaz city during 2012. Sampling and collection of data was performed by Ahvaz department of environment and meteorological organization. The analysis of sulfur dioxide data was performed by Excel software and AirQ model. The estimation of the impact on health, attributable to the exposure of air pollution to the target population was conducted using AirQ model, which estimated this impact to be related to specific air pollutants on a resident population in a certain area and period $(28,29)$. AirQ $_{2.2 .3}$ software was proved to be a valid and reliable tool to estimate the potential short-term effects of air pollution, predict health endpoints attributed to criteria pollutants, and allow the examination of various scenarios in which the emission rates of pollutants were varied. This model is a valid and reliable world health organization (WHO)-proved tool to estimate the potential short-term effects of air pollution. This model includes four screen inputs (supplier, quality assurance (AQ) data, location, parameter) and two output screens (table and figure) $(20,29)$. The most important part of the analysis is data processing which encompasses modification of temperature and pressure, primary processing (deletion, spreadsheet, and synchronization), secondary processing (code writing and condition correction), formulation and filtering. We calculated the cardiovascular deaths related to sulfur dioxide by AirQ $_{2.2 .3}$ based on utilizing the relative risk, attributable proportion and baseline incidence from WHO data $(28,29)$.

\subsection{Description of Study Area}

Ahvaz city, with a population of one million approximately, with an area of 8152 square kilometers, the capital of Khuzestan province, is located between $48^{\circ}$ to $49^{\circ} 29^{\prime}$ east of Greenwich meridian and between $31^{\circ}$ and $45 \mathrm{~min}$ utes to the north of the equator $(23,29)$. To perform this study, data was taken from Ahvaz Department of Environment (ADoE). The stations were located in downtown Old School of Public Health Bureau of Meteorology and head office of ADoE.

\subsection{Data Analysis}

For assessing of health impacts related to sulfur dioxide exposure in the ambient air of Ahvaz, we needed the city population, coordination (latitude and longitude), the number of stations and their data sets. All the statistical analyses were performed using Microsoft Excel program as well as statistical software packages with average and standard deviation. As mentioned, the most important part of the analysis was data processing which encompassed removal or recovery of missing figures, correction of temperature and pressure on the basis of meteorological data, code writing, formulation, and filtering. In terms of epidemiological parameters, relative risk, baseline incidence and attributable proportion, they were calculated based on previous studies of WHO. In addition to the total attributable cases, we could estimate the distribution of attributable cases in terms of concentration intervals of pollutant. The results were the excess cases of deaths and diseases associated with the given pollutant (sulfur dioxide).

\section{Results}

The primary and secondary standard of sulfur dioxide according to NAAQS in 24hourswas $150 \mu \mathrm{g} / \mathrm{m}^{3}$ (20). Table 1 shows that the annual mean of sulfur dioxide in Ahvaz was $160 \mu \mathrm{g} / \mathrm{m}^{3}$ in 2012 which was higher than the NAAQS standards. In view of sulfur dioxide concentrations, downtown "Naderi" and Bureau of Meteorology were the highest and the lowest stations during 2012, respectively. The yearly average, summer mean, winter mean and 98 percentile of sulfur dioxide concentrations in these stations are presented in Table 1.

\begin{tabular}{lccc}
\hline \multicolumn{2}{l}{ Table 1. Highest and Lowest Concentrations of Sulfur Dioxide Corresponding to Stations ${ }^{\text {a }}$} \\
\hline Parameter & Average in Ahvaz & \multicolumn{2}{c}{ Stations } \\
\cline { 2 - 4 } & & lowest Stations (Bureau of Meteorology) & Highest Stations (Downtown “Naderi”) \\
\hline Annual mean & $160 \pm 28.3$ & $75 \pm 17.3$ & $220 \pm 29.4$ \\
Summer mean & $46 \pm 9.4$ & $37 \pm 7.9$ & $75 \pm 15.7$ \\
Winter mean & $173 \pm 23.8$ & $81 \pm 18.7$ & $242 \pm 26.3$ \\
98 percentile & 171 & 96 & 281 \\
\hline
\end{tabular}

\footnotetext{
${ }^{\mathrm{a}}$ Data are presented in $\mu \mathrm{g} / \mathrm{m}^{3}$.
} 
According to Table 1, the highest sulfur dioxide concentration in Ahvaz city during 2012 occurred in winter which was $173 \pm 23.8 \mu \mathrm{g} / \mathrm{m}^{3}$.

Figure 1 shows the cumulative hospital admissions of respiratory disease and respiratory mortality versus sulfur dioxide. Cumulative cases of this health endpoint were estimated which was 25 in 2012; $80 \%$ of this number occurred in days with concentrations lower than $180 \mu \mathrm{g} / \mathrm{m}^{3}$. Twenty one persons were estimated as respiratory mortality within one year of exposure; $47 \%$ of these cases occurred in days with ozone levels not exceeding $90 \mu \mathrm{g} / \mathrm{m}^{3}$.

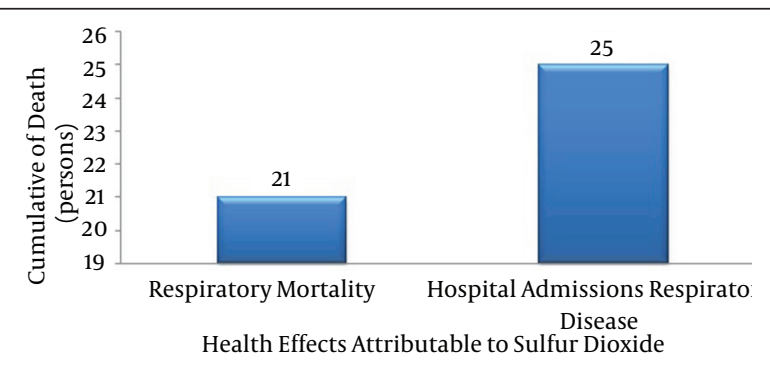

Figure 1. The Relationship Between Cumulative of Hospital Admissions for Respiratory Disease and Respiratory Mortality and Sulfur Dioxide
The relative risk (RR) and estimated attributable proportion (AP) percentage for respiratory mortality and hospital admissions of respiratory disease are presented in Table 2. The baseline incidence (BI) for this health endpoint for sulfur dioxide was66 per 105; so, the number of respiratory mortality cases was 21 ( $R R=1.0044$ and $\mathrm{AP}=1.8165 \%$ ) and for hospital admissions of respiratory disease it was101.4 per $10^{5}$; so, the number was $25(\mathrm{RR}=1.01$ and $\mathrm{AP}=4.0350 \%$ ) at the centerline of relative risk.

Respiratory mortality versus sulfur dioxide concentration is shown in Figure 2. The estimated cases attributed to sulfur dioxide for respiratory mortality at lower, central and higher RR were 8, 21, and 43, respectively; $63 \%$ of this number occurred in the days with concentrations lower than $150 \mu \mathrm{g} / \mathrm{m}^{3}$. It should be noted that $71 \%$ of the above number was corresponded to the days with concentrations below $200 \mu \mathrm{g} / \mathrm{m}^{3}$.

Figure 3 show that no one day in 2012 has been reaches the sulfur dioxide concentration below $\mu \mathrm{g} / \mathrm{m}^{3} 10$, In other words, in 2012, sulfur dioxide concentration was never below $10 \mu \mathrm{g} / \mathrm{m}^{3}$. The hospital admissions of respiratory disease cases with increase of the concentrations of sulfur dioxide to $20-120 \mu \mathrm{g} / \mathrm{m}^{3}$ have a uniform trend.

Table 2. Relative Risks, Attributable Proportions and Number of People With Respiratory Mortality (BI=66) and Hospital Admissions for Respiratory Disease (BI=101.4) Due to Sulfur Dioxide Exposure

\begin{tabular}{lccc}
\hline Estimate & \multicolumn{2}{c}{ Indicator } \\
\cline { 2 - 4 } & RR(Medium) & AP, \% & Attributable Excess Cases, Persons \\
\hline Respiratory mortality (down) & 1.0001 & 0.008 & 8.6 \\
Respiratory mortality (mediocre) & 1.0044 & 1.8165 & 21.2 \\
Respiratory mortality (up) & 1.011 & 4.4207 & 43.5 \\
Hospital admissions for respiratory disease (down) & 1.006 & 2.4607 & 15.8 \\
Hospital admissions for respiratory disease (mediocre) & 1.01 & 4.0350 & 25.8 \\
\hline Hospital admissions for respiratory disease (up) & 1.014 & 5.5593 & 35.6 \\
\hline
\end{tabular}

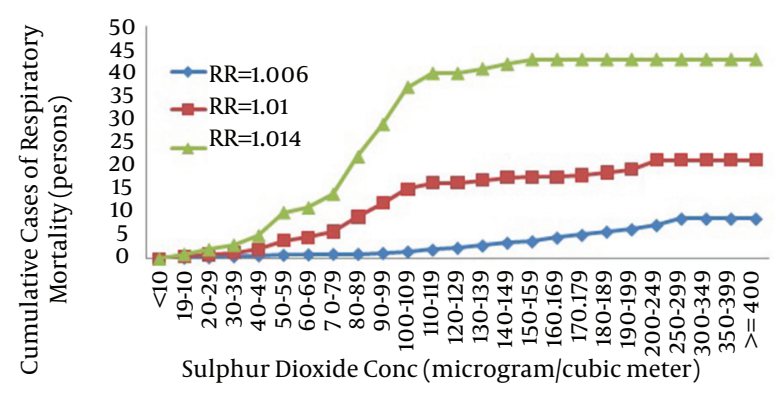

Figure 2. The Relationship Between Cumulative Numbers for Respiratory Mortality and Sulfur Dioxide Concentration

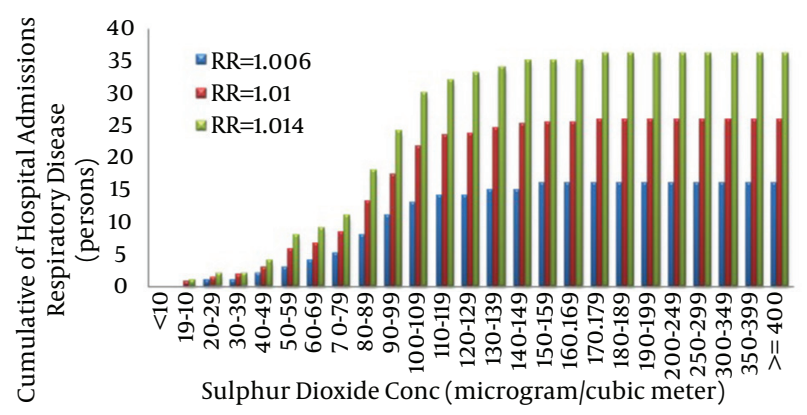

Figure 3. The Relationship Between Cumulative Numbers of Hospital Admissions for Respiratory Disease and Sulfur Dioxide Concentration 


\section{Discussion}

In this study, we estimated the hospital admissions for respiratory disease and respiratory mortality to be associated with short- and long-term fluctuations in concentrations of sulfur dioxide pollutant, using AirQ model in Ahvaz, Iran. Sum of the respiratory diseases attributed to sulfur dioxide in Ahvaz was 21 cases in 2012. The results showed that approximately, Ahvaz with $5 \%$ is one of the most polluted cities. The higher percentage of these deaths perhaps could be the result of higher average sulfur dioxide or because of sustained high-concentration days in Ahvaz. Table 1 shows that the 24-hour average of summer and winter of downtown "Naderi" and Bureau of meteorology were the highest and the lowest stations during 2012, respectively. Relative risk, the percentage, the attributable ratio and the respiratory mortality attributed to sulfur dioxide are estimated in Table 2. According to Table 2, the relative risk (RR) of hospital admissions for respiratory disease increased $0.34 \%$ in lieu to each $1 \mathrm{mg}$ increase of sulfur dioxide concentration $(0.18 \%$ per $\mathrm{CI}=$ $0.0 / 5$ and $0.96 \%$ per $\mathrm{CI}=0.95$ ). Figure 3 have illustrated the sulfur dioxide concentrations versus related health endpoint and average concentrations during years. The association of daily mortality and morbidity with shortterm variations in the ambient concentrations of air pollutants has been studied (30). In a similar work by Goudarzi et al. In 2009, the sulfur dioxide hygienic effects in Tehran (capital of Iran) were estimated. Based on their results, almost $7.82 \%$ and $3.6 \%$ of all cases of whole respiratory deaths and hospital admissions for respiratory disease were attributed to sulfur dioxide (31). In another study by Mohammadi et al. In 2009, the health effects of air pollutants in Ahvaz were calculated. Based on their results, approximately $4.03 \%$ of total respiratory deaths and $1.8 \%$ of hospital admissions for respiratory disease were related to sulfur dioxide (32). Zalaghi et al. (33) In 2010 in a survey regarding the health effects of air pollution in Ahvaz, Bushehr and Kermanshah concluded that approximately $4.4 \%$ in Ahvaz, 8.64\% in Kermanshah and $3.33 \%$ of total respiratory deaths were attributed to sulfur dioxide. According to a study by Sunyer et al. (34) increase of daily sulfur dioxide levels, two days in a row, can lead to cardiovascular and respiratory mortality. They found that an increase in the $10 \mu \mathrm{g} / \mathrm{m}^{3}$ daily average of sulfur dioxide led to an increase of $0.7 \%$ of all the cardiovascular admissions during two consecutive days (34). Lippmann et al. survey on health effects of air pollution in Detroit, the USA, showed that with an increase in the pollutant levels of $10 \mu \mathrm{g} / \mathrm{m}^{3}$ (daily average of sulfur dioxide), an increase of $2 \%$ in hospital admissions occurred (35). Studies in six Italian cities in 2001 showed that increase in daily average of sulfur dioxide was related with an increase of $2.8 \%$ in cardiovascular diseases (36). According to a study by Ballester in Valencia, Spain, the increase in sulfur dioxide levels increased the prevalence of circulatory diseases in the community (37).
This study was the second attempt to evaluate the health impacts of sulfur dioxide air pollutants in Ahvaz, Iran. Based on the results of this study, approximately $5 \%$ of the total hospital admissions for respiratory disease and respiratory mortality were attributed to respiratory sulfur dioxide. The greatest number of health effects was related to the high concentration of measured sulfur dioxide. Sulfur dioxide concentration was high compared to the standard values issued by The US. EPA (NAAQS guidelines' values). Although the results of this study were in line with the results of other researches around the world, since the geographic, demographic, and climate characteristics were different, there is still a high demand on further studies to specify local RR and BI. Careful monitoring of air pollution is necessary to reduce the health risks; air pollution can be reduced by limiting the emissions of pollutants from various sources such as changing the modes of transportation and reducing the energy consumption, especially the ones based on combustion sources. Finally, the survey results showed that implementation of basic actions to control sulfur dioxide and prevent it from entering to the stratosphere by decrease of consumption of gasoil fuel in industries and development of green space are essential. Accordingly, cost-effective measures and management schemes should be considered to abate air pollution concentrations and/or reduce the exposure of general population to air pollutants.

\section{Acknowledgements}

The authors would like to thank Razi Teaching Hospital, Clinical Research Development Center for the technical support and providing the facilities.

\section{Authors' Contributions}

Study concept, design and critical revision of the manuscript for important intellectual content: Mohammad Javad Mohammadi, Sahar Geravandi, Gholamreza Goudarzi, Mehdi Vosoughi Niri, Shokrollah Salmanzadeh, Ali Akbar Babaei, and Afshin Takdastan; drafting of the manuscript and advisor: Sahar Geravandi; performing the experiments: Mohammad Javad Mohammadi.

\section{Funding/Support}

This study was supported by Ahvaz Jundishapur University of Medical Sciences.

\section{References}

1. Samet JM, Zeger SL, Dominici F, Curriero F, Coursac I, Dockery DW, et al. The National Morbidity, Mortality, and Air Pollution Study. Part II: Morbidity and mortality from air pollution in the United States. Res Rep Health Eff Inst. 2000;94(Pt 2):5-70.

2. Galan I, Tobias A, Banegas JR, Aranguez E. Short-term effects of air pollution on daily asthma emergency room admissions. Eur RespirJ. 2003;22(5):802-8.

3. Wong CM, Ma S, Hedley AJ, Lam TH. Effect of air pollution on daily mortality in Hong Kong. Environ Health Perspect. 2001;109(4):335-40. 
4. Rich DQ, Mittleman MA, Link MS, Schwartz J, Luttmann-Gibson $\mathrm{H}$, Catalano PJ, et al. Increased risk of paroxysmal atrial fibrillation episodes associated with acute increases in ambient air pollution. Environ Health Perspect. 2006;114(1):120-3.

5. Trasande L, Thurston GD. The role of air pollution in asthma and other pediatric morbidities. J Allergy Clin Immunol. 2005;115(4):689-99.

6. Baccarelli A, Barretta F, Dou C, Zhang X, McCracken JP, Diaz A, et al. Effects of particulate air pollution on blood pressure in a highly exposed population in Beijing, China: a repeated-measure study. Environ Health. 2011;10:108.

7. Gent JF, Triche EW, Holford TR, Belanger K, Bracken MB, Beckett WS, et al. Association of low-level ozone and fine particles with respiratory symptoms in children with asthma. JAMA. 2003;290(14):1859-67.

8. Bateson TF, Schwartz J. Who is sensitive to the effects of particulate air pollution on mortality? A case-crossover analysis of effect modifiers. Epidemiology. 2004;15(2):143-9.

9. Krzyzanowski M, Cohen A, Anderson R, W. H. O. Working Group. Quantification of health effects of exposure to air pollution. Occup Environ Med. 2002;59(12):791-3.

10. Pan Z, Molhave L, Kjaergaard SK. Effects on eyes and nose in humans after experimental exposure to airborne office dust. Indoor Air. 2000;10(4):237-45.

11. Pope C3, Burnett RT, Thun MJ, Calle EE, Krewski D, Ito K, et al. Lung cancer, cardiopulmonary mortality, and long-term exposure to fine particulate air pollution. JAMA. 2002;287(9):1132-41.

12. Reed MD, Gigliotti AP, McDonald JD, Seagrave JC, Seilkop SK, Mauderly JL. Health effects of subchronic exposure to environmental levels of diesel exhaust. Inhal Toxicol. 2004;16(4):177-93.

13. Zallaghi E, Goudarzi G, Nourzadeh Haddad M, Moosavian SM, Mohammadi MJ. Assessing the Effects of Nitrogen Dioxide in Urban Air on Health of West and Southwest Cities of Iran. JundishapurJournal of Health Sciences. 2014;6(4):e23469.

14. Glad JA, Brink LL, Talbott EO, Lee PC, Xu X, Saul M, et al. The relationship of ambient ozone and $\mathrm{PM}(2.5)$ levels and asthma emergency department visits: possible influence of gender and ethnicity. Arch Environ Occup Health. 2012;67(2):103-8.

15. Clancy L, Goodman P, Sinclair H, Dockery DW. Effect of air-pollution control on death rates in Dublin, Ireland: an intervention study. Lancet. 2002;360(9341):1210-4.

16. Hedley AJ, Wong CM, Thach TQ, Ma S, Lam TH, Anderson HR. Cardiorespiratory and all-cause mortality after restrictions on sulphur content of fuel in Hong Kong: an intervention study. Lancet. 2002;360(9346):1646-52.

17. Kelly FJ. Oxidative stress: its role in air pollution and adverse health effects. Occup Environ Med. 2003;60(8):612-6.

18. Kinney PL, Lippmann M. Respiratory effects of seasonal exposures to ozone and particles. Arch Environ Health. 2000;55(3):210-6.

19. Ritz B, Yu F, Fruin S, Chapa G, Shaw GM, Harris JA. Ambient air pollution and risk of birth defects in Southern California. Am J Epidemiol. 2002;155(1):17-25.

20. Goudarzi G, Geravandi S, Salmanzadeh S, javad Mohammadi M, Zallaghi E. The number of myocardial infarction and cardiovascular death cases associated with sulfur dioxide exposure in ahvaz, iran. Archives of Hygiene Sciences. 2014;3(3):112-9.

21. Geravandi S, Mohammadi MJ, Goudarzi G, Ahmadi Angali K, Neisi AK, Zalaghi E. Health effects of exposure to particulate matter less than 10 microns (PM10) in Ahvaz. J Qazvin Univ Med Sci.
2014;18(5):45-53.

22. Taghavirad SS, Davar H, Mohammadi MJ. The a study on concentration of BETX vapors during winter in the department of ports and shipping located in one of the southern cities of Iran. Inte J Cur Life Sci. 2014;4(9):5416-20.

23. Zallaghi E, Goudarzi G, Geravandi S, Javad M. Epidemiological Indexes Attributed to Particulates With Less Than 10 Micrometers in the Air of Ahvaz City During 2010 to 2013. Health Scope. 2014;3(4):e22276.

24. Goudarzi G, Geravandi S, javad Mohammadi M, Ghomaishi A, Salmanzadeh S. Cardiovascular death, Respiratory mortality and Hospital Admissions Respiratory Disease related to PM10 Exposure in Ahvaz, Iran. Iranian Journal of Health, Safety and Environment. 2014;1(4):159-65.

25. Goudarzi G, Geravandi S, Vosoughi M, javad Mohammadi M, sadat Taghavirad S. Cardiovascular deaths related to Carbon monoxide Exposure in Ahvaz, Iran. Iranian Journal of health, Safety and environment. 2014;1(3):126-31.

26. Katsouyanni K, Touloumi G, Spix C, Schwartz J, Balducci F, Medina S, et al. Short-term effects of ambient sulphur dioxide and particulate matter on mortality in 12 European cities: results from time series data from the APHEA project. Air Pollution and Health: a European Approach. BMJ. 1997;314(7095):1658-63.

27. Schwartz J. Air pollution and hospital admissions for respiratory disease. Epidemiology. 1996;7(1):20-8.

28. Geravandi S, Neisi AK, Goudarzi G, Vousoghi Niri M, Mohammadi MJ. Estimation of Cardiovascular and Respiratory Deaths Related to Ozone Exposure in Ahvaz, During 2011. Journal of Rafsanjan University of Medical Sciences. 2015;13(11):1073-82.

29. Mohammadi MJ, Godini H, Khak MT, Daryanoosh SM, Dobaradaran S, Goudarzi G. An Association Between Air Quality and COPD in Ahvaz, Iran. 2015.

30. Gryparis A, Forsberg B, Katsouyanni K, Analitis A, Touloumi G Schwartz J, et al. Acute effects of ozone on mortality from the "air pollution and health: a European approach" project. Am J Respir Crit Care Med. 2004;170(10):1080-7.

31. Goudarzi G. . Quantification of health effects of air pollution in Tehran and determining the impact of a comprehensive program to reduce air pollution in Tehran on the third axis. [PhD Thesis.]. Tehran, Iran: Tehran University of Medical Sciences; 2008.

32. Mohammadi MJ. . Studied hygienic effects of air pollution in town Ahvaz in 2009 with model Air Q. [MSc Thesis.]. Ahvaz, Iran: Ahvaz Jundishapur University of Medical Sciences; 2009.

33. Zalaghi E. . Survey of health Effects of Air Pollution Ahvaz, Bushehr and Kermanshah with Use of AIRQ Model. [MSc Thesis, .]. Ahvaz, Iran: Islamic Azad University, Science and Research Branch, Ahvaz; 2010.

34. Sunyer J, Ballester F, Tertre AL, Atkinson R, Ayres JG, Forastiere F, et al. The association of daily sulfur dioxide air pollution levels with hospital admissions for cardiovascular diseases in Europe (The Aphea-II study). Eur Heart J. 2003;24(8):752-60.

35. Lippmann M, Ito K, Nadas A, Burnett RT. Association of particulate matter components with daily mortality and morbidity in urban populations. Res Rep Health Eff Inst. 2000;(95):5-72.

36. Biggeri A, Baccini M, Gruppo collaborativo E. [Short-term effects of air pollution in Italy: risk heterogeneity from 1996 to 2005]. Epidemiol Prev. 2009;33(6 Suppl 1):95-102.

37. Ballester F, Tenias JM, Perez-Hoyos S. Air pollution and emergency hospital admissions for cardiovascular diseases in Valencia, Spain. J Epidemiol Community Health. 2001;55(1):57-65. 